\title{
Lung Cancer Treatment Decision-Making by Descriptive Decision-Making Framework
}

\author{
Elhum Nusrat \\ Information Science and Control Engineering \\ Graduate School of Engineering \\ Nagaoka University of Technology, \\ 1603-1 Kamitomioka, Nagaoka, Niigata 940-2188, \\ Japan
}

\author{
Koichi Yamada \\ Management and Information Systems Science \\ Faculty of Engineering \\ Nagaoka University of Technology, \\ 1603-1 Kamitomioka, Nagaoka, Niigata 940-2188, \\ Japan
}

\begin{abstract}
The need of shared decision-making has been discussed by researchers since last few decades and is being practiced in several fields. Medical field is also experiencing its consequent positive impact. Keeping this ongoing trend in mind, this paper proposes a theory-based approach of descriptive decision-making (DM) under the realm of uncertainty along with its application to DM of treatment alternative of newly-diagnosed lung cancer patients. The novelty of this paper is: (1) A discussion on our proposed descriptive decision-making framework that holds the option of incorporating multiple sources of information and a distinctive rule for combining these evidences originated from multiple sources, (2) an application of this DM framework to discuss the variability of decisions regarding treatments of newly-diagnosed lung cancer patients based on their attitudes towards uncertainty.
\end{abstract}

\section{General Terms}

Decision-making under uncertainty.

\section{Keywords}

Uncertainty; decision-making; Dempster-Shafer theory; Prospect Theory; combination of evidences; lung cancer diagnosis and staging.

\section{INTRODUCTION}

Making decisions is undisputedly one of the most essential activities of human beings. In this world of uncertainty, decision-making (DM) becomes a part and parcel of our daily life. In our everyday activities, we have to face variety of alternatives and we are obliged to determine one of those options. In most of these cases, human beings have to make decisions without knowing the outcomes appropriately. Models of decision-making can be classified into two groups: Normative or prescriptive and Descriptive decision models. A normative decision model deals with how decisions should be made. The word 'should' can have different interpretations. But most of the decision scientists agree that it refers to the prerequisites of rational decision making. Rational behavior is typified by a decision-maker who has a "well-organized and stable system of preferences and a skill in computation that enables him to calculate, for the alternative courses of action that are available to him, which of these will permit him to reach the highest attainable point on his preference scale"[1]. Therefore, a normative decision model is a model about how decisions should be made in order to be rational [2]. Extensive researches have proved that people are not always rational while making decisions. Various paradoxes such as Allais paradox [3] and Ellsberg paradox [4] etc. have been reported. Therefore, another type of decision-making was researched that explains the paradoxes that violate normative model. Both descriptive and normative DM theories possess individual characteristics. Descriptive decision-making describes what people with different attitudes actually accomplish in case of decision-making [5]. Descriptive models use cognition to explain decision-making; however, normative theories consist of "rationalistic" tenets that show how decision makers should decide. Reaching any decision in descriptive DM is influenced by psychological elements.

In this paper, a framework of descriptive DM (NY-DDM) [6] has been proposed that explains the decision variability at different phenomenon of attitude rather than providing an optimum solution which is the basic goal of any normative decision-making framework. Using this DM framework, we have demonstrated a DM problem of newly-diagnosed lung cancer patient's treatment alternative and explained the decision variability regarding treatments based on their attitudes towards uncertainty. In other words, this paper proposes a descriptive decision-making framework for deciding lung cancer treatment alternatives by the patients with different mindset towards uncertainty.

A cancer diagnosis brings about an abrupt transition into a new world. From the very beginning, complicated treatment decisions are presented; schedules are restructured around treatments and scans; and physical, emotional, and spiritual challenges emerge. Throughout the cancer trajectory, including diagnosis, treatment, remission, patients and caregivers face numerous dynamic needs and difficult decisions. Traditionally, medical practitioners played a paternalistic role in treatment decisions and the patients mostly abided by the decisions. But there has been revolutionary change in medical fields since few decades and the patients are being more and more encouraged to get involved in treatment decisions. In fact, researches on patient decision-making have an extensive history. In early 1980s, researchers started experiments in the field of urology involving advanced technology. Multiple studies have shown that the combination of physicians' knowledge and patient's participation improved patient satisfaction and physician's time [7, 8]. Although the traditional school of thought argued that involving patients in choosing treatment can make them burdened or can be unfavorable for them, yet no such evidence exists to support this issue [9]. In reality, there have been evidences that patients feel more active when being included in health-care decisions [10]. Apart from the physician's advice of treatment procedures, a patient has his/her own freedom to decide from an array of alternatives considering the trade-offs. It has been suggested that 
behavioral as well as demographic influences are observed in treatment choice preferences. Like all other cancers, lung cancer also poses a great impact on the patient's life. The patients as well as the families or caregivers may be required to make significant treatment decisions. Later, difficult choices include whether to continue curative treatments or focus on palliative care and, if the latter is chosen, which palliative options are most appropriate. Most of these decisions are taken in the realm of uncertainty. Therefore, the objective of this paper is to explain and analyze the decisions of a lung cancer patient through the proposed DM framework composed of Dempster-Shafer Theory (DST) [11] and Prospect Theory (PT) [5] when the staging information is yet to be decided. In course of the research, we have also investigated how evidence combination can facilitate the staging procedure of lung cancer in order to reach an appropriate treatment decision because treatment decision is highly dependent on staging of lung cancer. Therefore, this paper also summarizes our findings of [12]. The organization of this paper is as follows: Section 2 discusses the decisionmaking models in the literature. Section 3 briefly describes the proposed NY-DDM framework. Section 4 illustrates the DM problem of treatment alternative selection of lung cancer patients and explains how NY-DDM can be fitted into this problem. Section 5 includes the result and analysis of the decisions and Section 6 summarizes the paper.

\section{RELATED WORKS ON DECISION- MAKING UNDER UNCERTAINTY}

In the year 1921, Knight [13] wrote a paper where he showed distinction between risk and uncertainty. This theory seemed to have some intuitive appeal to Ellsberg [4]. Since then, it was evident that there was a sheer need for decision under uncertainty when no probabilities are given [14]. Schemeidler [15] resolved this problem by extending rank-dependent utility (RDU) to the realm of uncertainty, which had been the first nonexpected utility model for decision-making under risk proposed by Quiggin [16].

The essence of RDU under risk is that the decision weight in the prospect - which is the sum of products of probability and utility for every state of nature in the case of the expected utility theory - is not just a probability or a weighted probability but is defined by cumulative probabilities called rank with a probabilistic weighting function. RDU under uncertainty proposed by Schemeidler [15] has almost the same structure of prospects. However, each term of the prospect is a product of decision weight and utility for a set of states of nature, not for every state of nature. The restrictions are that the sets in the prospect must partition the whole states of nature as well as every state of nature in a set must have an outcome with the same utility.

Another model of decision-making under uncertainty is introduced in generalized expected utility (GEU) [17, 18] model where basic belief assignment (bba) of DST has been used to represent uncertainty. DM with GEU model chooses the alternative that maximizes the next equation.

$$
U_{g e u}\left(a_{i}\right)=\sum_{k} m\left(S_{k}\right) \bullet V\left(a_{i}, S_{k}\right),
$$

where $m\left(S_{k}\right)$ is a basic belief assignment and $S_{k}$ is a focal element representing a set of states of nature. $V\left(a_{i}, S_{k}\right)$ is a utility evaluation depending on the alternative $a_{i}$ and $S_{k}$, and can be given by a parametric function called OWA operator $[18,19]$, whose parameters could be determined by the attitude (equative, pessimistic, optimistic, etc.) of the decision-maker to non-specificity or ignorance of the states in $S_{k}$. This model has no restriction on $S_{k}$ in equation (1) unlike RDU under uncertainty. However, this is a normative model, not a descriptive model.

Among the recent works, a DM model under uncertainty called Cautious OWA with Evidential Reasoning (COWAER) is introduced in [20] as an extension of [18]. It is also relevant to mention Cumulative Prospect Theory (CPT) [21] in this section that falls under the category of descriptive DM model under uncertainty. CPT is an extension of prospect theory incorporating rank-dependent utility theory by Schemeidler. However, it also has the same restrictions as RDU under uncertainty mentioned above. Another descriptive DM model under uncertainty is proposed by Tamura et al. [22-23] as an extension of PT. A limitation of this model is that it cannot implement various decision attitudes other than the typical three; equative, pessimistic and optimistic. For example, it does not explain the median approach as well as 2nd pessimistic/optimistic. Next, Tamura et al. model lacks in consideration about the difference between the weighting function of probability and the one of $b b a$.

The key differences between our proposed model, NY-DDM and the above mentioned models can be summarized as follows: 1) uncertainty by $b b a$ is more general than uncertainty defined on a partition, and can represent all realms of DM, that is, realms of certainty, risk, uncertainty and/or ignorance, 2) Our model incorporates the evidences gathered from multiple information sources and the combination of evidences, 3) it can deal with various decision attitudes to non-specificity or ignorance thanks to the capability for converting any uncertainty model with OWA operator to a risk model, 4) the incorporation of PT has given NY-DDM the characteristic of a descriptive DM model. While our model has advantage of the above four points over the theories discussed here, we do not claim that it contains them as a part, because the idea of the rank dependent theory is not contained.

\section{PROPOSED DESCRIPTIVE DECISION-MAKING FRAMEWORK: NY-DDM}

NY-DDM initiates with an Evidential Decision Making Problem (EDMP). EDMP has similarity to the conventional definition of decision making in different literature where $A=$ $\left\{a_{i} \mid i=1 \ldots . N\right\}$ is the set of alternatives, $S=\left\{s_{j} \mid j=1, \ldots, M\right\}$ is the states of nature and the outcome set $O=\left\{o_{i j} \mid o_{i j}=f\left(a_{i}, s_{j}\right)\right\} \quad$ and the utility function $u_{i j}=u\left(o_{i j}\right)$. The uncertainty is defined on the states of nature $S$ by a function $m(B)$, where $B \subset S . m(B)$ represents the basic belief assignment $(b b a)$. We chose the DempsterShafer Theory (DST) of Evidence due to its capability of expressing more than one type of uncertainty. Decisionmaking is practically performed under the realm of certainty, risk, uncertainty and/or ignorance. Our definition of EDMP satisfies all of these realms by giving an appropriate $b b a$. The approach we have considered to solve a DM problem under uncertainty is the probability approximation and we have approximated the $b b a$ to probability. In our model, a DM problem with uncertainty is approximated by one of DM with 
risk, depending on the attitudes to non-specificity or ignorance.

A seemingly standard way of approximation from $b b a$ to probability is the one by equidistribution [24] where the mass is equally distributed over the states of the focal element.

$$
P_{\text {app }}\left(s_{j}\right)=\sum_{s_{j} \in S_{k}} \frac{m\left(S_{k}\right)}{\left|S_{k}\right|}
$$

When the mass function is defined on a total ordered set, or a set whose elements have a numerical attribute as in this case, we could assign probability distributions of the worst case and the best case which are consistent with the mass function; the best case assigns the whole mass of $S_{k}$ namely $m\left(S_{k}\right)$, to the largest/best element(s) $s_{b e s t}^{(k)} \in S_{k}$, and the worst case to the smallest/worst element(s) $s_{\text {worst }}^{(k)} \in S_{k}$. Note that $s_{\text {best }}^{(k)}$ and $s_{\text {worst }}^{(k)}$ depend on alternative $a_{i}$, because utility is a function of a pair of $a_{i}$ and $s_{j}$. Therefore, $P_{\text {pes }}\left(s_{j} \mid a_{i}\right)$, $\left(P_{o p t}\left(s_{j} \mid a_{i}\right)\right)$ is the probability distribution in the case where we assume that $s_{\text {worst }}^{(k)}\left(s_{\text {best }}^{(k)}\right)$ happens with a probability equal to $m\left(S_{k}\right)$, when the decision-maker chooses $a_{i}$ and thus the name Pessimistic (Optimistic) probability distribution respectively. The equations of Pessimistic and Optimistic distribution are as follows:

$$
\begin{gathered}
P_{\text {pes }}\left(s_{j} \mid a_{i}\right)=\sum_{k} m_{\text {pes }}\left(s_{j}, S_{k} \mid a_{i}\right), \\
P_{\text {opt }}\left(s_{j} \mid a_{i}\right)=\sum_{k} m_{\text {opt }}\left(s_{j}, S_{k} \mid a_{i}\right), \\
m_{\text {pes }}\left(s_{j}, S_{k} \mid a_{i}\right)=\left\{\begin{array}{l}
\frac{m\left(S_{k}\right)}{N_{\text {pes }}}, \text { if } \mathrm{s}_{\mathrm{j}} \in S_{k}, u\left(o_{i j}\right)=\operatorname{Min}_{s_{h} \in S_{k}} u\left(o_{i h}\right) \\
0, \text { otherwise }
\end{array}\right. \\
m_{\text {opt }}\left(s_{j}, S_{k} \mid a_{i}\right)=\left\{\begin{array}{l}
\frac{m\left(S_{k}\right)}{N_{\text {pes }}}, \text { if } \mathrm{s}_{\mathrm{j}} \in S_{k}, u\left(o_{i j}\right)=\operatorname{Max}_{s_{h} \in S_{k}} u\left(o_{i h}\right), \\
0, \text { otherwise }
\end{array}\right.
\end{gathered}
$$

where $N_{\text {pes }}$ and $N_{\text {opt }}$ are numbers of $s_{j} \in S_{k}$ satisfying $u\left(o_{i j}\right)=\underset{s_{h} \in S_{k}}{\operatorname{Min}} u\left(o_{i h}\right)$ and satisfying $u\left(o_{i j}\right)=\underset{s_{h} \in S_{k}}{\operatorname{Max}} u\left(o_{i h}\right)$, respectively. Moreover, it is also possible to show that any GEU model with OWA operator can be transformed into a DM under risk. This fact lets us discuss descriptive model of DM under uncertainty in the framework of DM under risk. (Please refer to [6] for detailed explanation and proof). We can infer from the above discussion that a DM problem under uncertainty with GEU and OWA operator could be transformed into a DM problem under risk equivalent to the original one.

By approximating uncertainty to probability, the EDMP is converted into three different problems of DM under risk (We could convert it to many other DM problems under risk depending on the attitude of the decision maker). At this point, applying PT will lead us to a descriptive model of DM under risk corresponding to DM under uncertainty with OWA operator. In PT, the choice of alternatives is determined by the sum of products of two very important functions: the value function and the weighting function [5]. In value function $v(x), x$ is either gain or loss. If the value $x$ is greater (less) than a neutral reference point, then the outcome has a gain (loss). According to PT, people value gains or loss differently and therefore $v(x)$ reflects the subjective value of that outcome. The value function in original $\mathrm{PT}$ is:

$$
v(x)=\left\{\begin{array}{cc}
x^{\alpha}, & \text { if } \quad x \geq 0 \\
-\lambda(-x)^{\alpha}, & \text { if } x<0 .
\end{array}\right.
$$

For $\alpha<1$, the value function exhibits risk aversion over gains and risk seeking over losses. Furthermore, if $\lambda$ (loss-aversion coefficient) is greater than one, individuals are more sensitive to losses than gains [25]. Furthermore, the weighting function $\pi(p)$ used in this paper is as follows:

$$
\pi(p)=\frac{p^{\gamma}}{\left[p^{\gamma}+(1-p)^{\gamma}\right]^{1 / \gamma}}, \quad 0<\gamma \leq 1
$$

As we mentioned in Section 2, NY-DDM has the advantage of deriving various attitudes including the $2^{\text {nd }}$ optimistic/pessimistic, half-/semi-/quarter optimistic and pessimistic attitudes and median approaches [26] which were unexplained by the previous descriptive DM models under uncertainty. Also, this model removes the problem of considering the difference between weighting function of probability and the one of $b b a$ since we have converted the EDMP into a probabilistic decision-making problem.

The importance of multiple pieces of evidences stemming from different sources is enormous in belief theory based DM problems. These sources provide different assumptions for the same universal set and almost all combination rules assume that these sources are independent. We have also considered the issue of 'multiple sources' in our framework and have proposed a new combination rule with weighted average as an improvement of Murphy's combination rule [27]. The weight can be assigned by using the reliability of each source being considered. Suppose, there are $n$ sources of evidence having the reliability of $r_{1}, r_{2}, \ldots, r_{n}$, and evidence from each source $i$ provides a mass $m_{i}$ for a focal element. Then, the weighted average mass $\bar{m}$ of the focal element is expressed by the following equation:

$$
\bar{m}=\frac{\sum_{i=1 \ldots . . n} m_{i} \bullet r_{i}}{\sum_{i=1 \ldots n} r_{i}}
$$

We have added a brief explanation in Section 4 to show that evidence combined by this rule can perform better in lung cancer staging procedure in comparison to the other conventional rules of combination. (Please refer to [12] for details). 


\section{TREATMENT DECISION-MAKING OF A LUNG CANCER PATIENT}

Lung cancer is one of the three most common cancers diagnosed each year. Around 41,400 people are diagnosed with lung cancer in the UK each year whereas in USA, the estimated number of new cases of lung cancer for 2012 is 226,160 with the estimated death of 160,340 people which is the highest among all common cancers. Between the two main types of lung cancer, about $87 \%$ are of NSCLC (Non small cell lung cancer) type that spreads slowly than small cell lung cancer (SCLC). It is indeed life threatening and un-treated lung cancer surely leads to death. Studies show that several factors such as external recommendation, intrinsic treatment characteristics, patients' and their supporters' own impressions and economic considerations are the most common factors of treatment decisions for non-malignant diseases whereas treatment efficiency (from the viewpoint of physician as well as patient) gets the top-most priority in case of life threatening diseases such as a disease like cancer. We are dealing with a problem where the patient has recently been diagnosed with cancer and the stage of cancer is yet to be diagnosed. So, the correct stage of cancer is still uncertain to the patient. Cancer staging requires a couple of diagnosis both physical tests and pathological findings and these serve as multiple sources of information. These pieces of evidences can be combined to generate proper staging information. We assume that the patient is not completely aware of cancer stage thereby indicating the uncertainty of the problem and thus treatment decision-making can be fitted into our descriptive DM framework under uncertainty.

\subsection{Problem Formulation}

An EDMP includes the set of states of nature $S$, set of alternatives $A$ and the set of outcomes $O$ for each state and alternative pair $\left(a_{i}, s_{j}\right)$ and utility values for each outcome.

\subsection{States of Nature}

The set of states of nature consists of the various stages being considered in the trajectory of lung cancer diagnosis. The stage of cancer implies how big it is and how far it has spread. In order to plan the best treatment as well as analyze the prognosis, staging of cancer is very important. Both number staging system and the TNM classification system ( $T$ : tumor characteristics including size, location and local invasion, $N$ : regional lymph node involvement and $M$ : metastasis status) are being used in staging lung cancer. We have considered the number staging system in this study and the set of states of nature $S$ includes the following 10 elements: $S=\{n c, o c, s 0$, $s 1 a, s 1 b, s 2 a, s 2 b, s 3 a, s 3 b, s 4\}$ where $n c$ implies no cancer, $o c$ implies occult stage, $s O$ implies stage 0 . (Please refer to [28] for detail descriptions and differences among the stages)

\subsection{Basic Belief Assignment and Combination of Evidences}

Basic Belief Assignment or $b b a$ is the assigned mass to the elements of the frame of discernment. In lung cancer treatment DM problem, the uncertainty is about which stage the patient belongs to. This information about stage can be obtained from various diagnostic methods and combination of evidences can facilitate the staging of the patient. At the very outset, a physician checks the symptoms and signs of lung cancer in course of diagnosis. But as a matter of fact, the symptoms and signs of lung cancer are difficult to be distinguished from those of other lung diseases. Therefore, when one or some of these symptoms are visible in a patient, he is suggested to have a Chest X-ray to get further details. Yet, there may be suspicion of lung cancer even after having chest X-ray. In order to be certain, clinical examination, blood tests, CT scan are requested to perform by the physician. Whenever the clinical examinations cannot produce certain decisions, further tests are carried out such as CT scan, bronchoscopy, sputum cytology or needle biopsy etc. Table 1 shows the categories of examination a patient usually goes through during lung cancer diagnosis and staging along with their reliabilities.

Table 1. List of Information Sources for Lung Cancer Staging and Their Reliabilities

\begin{tabular}{|c|c|c|}
\hline Categories & $\begin{array}{c}\text { Diagnosis and Staging } \\
\text { Information sources }\end{array}$ & $\begin{array}{c}\text { Reliability } \\
\text { of the } \\
\text { sources }\end{array}$ \\
\hline $\begin{array}{c}\text { Physical } \\
\text { Examination }\end{array}$ & Symptoms and Signs & 0.30 \\
\hline $\begin{array}{c}\text { Laboratary tests } \\
\text { and Imaging }\end{array}$ & $\begin{array}{c}\text { Sputum Cytology, Tumor } \\
\text { markers, Chest X-ray, CT, PET, } \\
\text { PET-CT, SPECT, FDG- PET, } \\
\text { Ultrasound. }\end{array}$ & 0.60 \\
\hline $\begin{array}{c}\text { Tissue } \\
\text { Diagnosis }\end{array}$ & $\begin{array}{c}\text { Bronchoscopy,Mediastinoscopy, } \\
\text { thoracoscopy,Transthoracic } \\
\text { needle aspiration (TTNA), Fine } \\
\text { Needle biopsy (FNA), } \\
\text { Endoscopic ultrasound (EUS), } \\
\text { VATS, Thoracoscopy. }\end{array}$ & 0.95 \\
\hline
\end{tabular}

Evidences collected from all of these sources are combined by the combination rule proposed in [12] in our DM framework. Let us explain a scenario. Suppose, when a patient shows several symptoms that match the ones with that of lung cancer, the belief assignments provided by the physical examination are: $m_{l}(\{s 0\})=0.30, m_{l}(\{o c\})=0.70$. Next, the imaging results express higher belief for 'no cancer'. So, $m_{2}(\{n c\})=0.70$, $m_{2}(S)=0.30$, which means the results suggest no cancer with belief of 0.70 but still there remains complete ignorance with the rest of belief. Later on, from tissue diagnosis, it was suspected that the patient may not possess any cancer; even if there is any minor presence of such, it is unlikely to be a major one. This can be stated as: $m_{3}(\{n c\})=0.90$ and $m_{3}(\{n c$, $s 0\})=0.10$. If we apply Dempster's rule of combination [29], we come up with a misleading scenario stating that the patient certainly has cancer ignoring the opinion provided by the majority of evidences, $m_{2}(\{n c\})=0.70$ and $m_{3}(\{n c\})=0.90$. In other words, loss of majority opinion occurs in this case as shown in Table 2.

Our proposed combination method [12] can resolve the problems created by Dempster's rule. The proposed combination method includes the reflection of the reliability of sources i.e. the evidences from the reliable sources are weighed heavily while assigning low weight to the evidences obtained from the less reliable ones. In order to have a clinically useful stage classification scheme for lung cancer diagnosis, the most reliable evidences are usually obtained from tissue diagnosis; imaging results are the next one and evidences from physical examination are considered to be the least reliable one. Therefore, in [12], we have examined several major combination rules as well as unreliability discounting, and proposed weighted averaging instead of simple average in Murphy's combination rule. 
Table 2. Evidence Combination by Dempster's Rule and Proposed Rule

\begin{tabular}{|c|c|c|c|}
\hline Given BBA & $\begin{array}{c}\text { Dempster's } \\
\text { Combination Rule }\end{array}$ & Weighted Average & $\begin{array}{c}\text { Combined Evidence by } \\
\text { Proposed Combination } \\
\text { Rule }\end{array}$ \\
\hline$m_{1}(\{s 0\})=0.30$, & & $m(\{n c\})=0.69$ & $m(\{n c\})=0.90$ \\
$m_{1}(\{o c\})=0.70$, & $m(\{o c\})=0.11$ & $m(\{o c\})=0.05$ \\
$m_{2}(\{n c\})=0.70, m_{2}(S)=0.30 ;$ & $m(\{s 0\})=1.0$ & $m(\{s 0\})=0.05$ & $m(\{s 0\})=0.02$ \\
$m_{3}(\{n c\})=0.90$, & $m(\{n c, s 0\})=0.05$ & $m(\{n c, s 0\})=0.02$ \\
$m_{3}(\{n c, s 0\})=0.10$ & & $m(S)=0.10$ & $m(S)=0.01$ \\
\hline
\end{tabular}

Table 3. BBA Table

\begin{tabular}{|l|l|}
\hline Cases & \multicolumn{1}{c|}{ Combined BBA Values } \\
\hline Case 1 & $m(\{n c\})=0.90, m(\{o c\})=0.05, m(\{s 0\})=0.02, m(\{n c, s 0\})=0.02, m(S)=0.01$ \\
\hline Case 2 & $m(\{s 1 a\})=0.14, m(\{s 2 a\})=0.54, m(\{n c, o c\})=0.03, m(\{s 0, s 1 a\})=0.05, m(\{s 1 a, s 1 b\})=0.24$ \\
\hline Case 3 & $m(\{s 4\})=1.00$ \\
\hline Case 4 & $m(\{s 1 a, s 2 a\})=0.75, m(\{s 1 a\})=0.25$. \\
\hline Case 5 & $m(\{s 3 b\})=1.00$ \\
\hline Case 6 & $m(\{o c\})=0.30, m(\{s 0\})=0.20, m(\{s 1 a\})=0.30, m(\{o c, s 0\})=0.20$ \\
\hline Case 7 & $m(\{o c\})=0.30, m(\{s 0\})=0.20, m(\{s 1 a\})=0.30, m(S)=0.20$ \\
\hline Case 8 & $m(\{o c, s 0, s 1 a\})=0.20, m(\{s 1 a, s 1 b\})=0.20$, \\
\hline Case 9 & $m(\{s 1 a, s 3 a, s 3 b, s 4\})=0.55, m(S)=0.05$. \\
\hline Case 10 & $m(\{s 1 a, s 1 b\})=0.60, m(S)=0.25, m(\{o c, s 0\})=0.15$ \\
\hline
\end{tabular}

Table 4. List of Alternatives

\begin{tabular}{|c|c|l|}
\hline \multirow{4}{*}{ Alternative } & Sub-types & Description \\
\hline \multirow{4}{*}{ Surgery } & L1 & Video-assisted thoratic surgery (VATS): early stage cancers \\
\cline { 2 - 3 } & L2 & Segmentectomy or wedge resection:Part of the lobe is removed. \\
\cline { 2 - 3 } & L3 & Lobectomy: A section of the lung is removed \\
\hline \multirow{4}{*}{ Chemotherapy } & L4 & Pneumonectomy: An entire lung is removed. \\
\cline { 2 - 3 } & L1 & Neoadjuvent therapy: Chemo with radiation before surgery. \\
\cline { 2 - 3 } & L2 & Adjuvent therapy: Along with radiation after surgery. \\
\cline { 2 - 3 } & L3 & Chemo as a main threatment \\
\hline \multirow{4}{*}{ Radiation Therapy } & L4 & Second-line treatment with a single drug for advanced stage cancer. \\
\cline { 2 - 3 } & L1 & Steriotactic Radiation: Early stage cancer. \\
\cline { 2 - 3 } & L2 & Intensity Modulated Radiation Therapy (IMRT) \\
\hline \multirow{3}{*}{ Targeted Therapies } & L3 & 3D-CRT \\
\cline { 2 - 3 } & L4 & Internal Radiation Therapy \\
\cline { 2 - 3 } & L1 & Drugs that target tumor blood vessel growth (Angiogenesis) \\
\cline { 2 - 3 } & L2 & Drugs that target EGFR (Epidermal Growth Factor Receptor) \\
\hline \multirow{3}{*}{ Clinical Trials } & L3 & Drugs that target ALK gene \\
\cline { 2 - 3 } & L4 & Complementary and alternative therapy \\
\cline { 2 - 3 } & L1 & Trials on Physical and Behavioral therapy :Trial on supportive care \\
\cline { 2 - 3 } & L2 & Pre- and Post-surgery trials \\
\hline No Cancer treatment & L3 & Biomarker/Laboratory/Diagnostic Trials \\
\hline \multirow{2}{*}{} & L4 & Trials on Treatment \\
\hline
\end{tabular}

The weight is assigned by using the reliability of each source in staging of lung cancer. The weighted averaged mass values are obtained by Eq. [9] and the averaged mass values are combined to itself by Dempster's combination rule mentioned below:

$$
\begin{array}{r}
m_{D}(A)=\frac{\sum_{X \cap Y=A} m_{1}(X) \bullet m_{2}(Y)}{1-K} \\
K=\sum_{X \cap Y=\phi} m_{1}(X) \bullet m_{2}(Y)
\end{array}
$$

where, $A \neq \phi$ and two $b b a$ 's $m_{1}$ and $m_{2}$ are supposed to be obtained from two independent sources. The obtained weighted average and the combined belief assignment by our proposed combination rule are shown in Table 2 for the similar case. Following the similar method, lung cancer staging evidences collected from three different sources are combined in this paper and 10 cases have been presented in Table 3.

\subsection{Alternatives}

The set of alternatives consists of various treatment options offered to a lung cancer patient. Surgery, Chemotherapy, Radiation therapy, Targeted Therapy and Clinical Therapy are the standard treatments used by most of the oncologists. There 
are also variety and/or combination of these treatments depending on the stage of cancer and obviously on patient's overall health condition. In the cancer treatment scenario, the patients who guess that the form of their current ailment is cancer do indulge in cancer detection diagnosis. But, many times the diagnosis results disapprove cancer and hence no form of cancer treatment is offered to the patient. Thus, in this study, we have also considered 'No cancer treatment' as an alternative along with the mentioned cancer treatments. Table 4 illustrates 21 alternatives we have considered in this paper.

\subsection{Outcomes and Utility Values}

In this DM problem, the consideration of outcome set for treatment decision depends on 4 factors: cost or expense of treatment $(C)$, treatment efficiency $(T)$, 5-year survival rate $(S)$ and side effects $(E)$ and the outcome set can be given by a quadruplet of $O$. The outcomes can be defined by the Cartesian product of the following sets: $O=O_{C} \times O_{T} \times O_{S} \times O_{E}$ where $O_{C}=\{$ Very Expensive:0, Expensive:1, Moderately Expensive:2, Inexpensive: $\}\}, O_{T}=\{$ No Recovery:0, Slow Recovery: 1, Moderate Recovery:2, Fast Recovery: 3\}, $O_{S}=\{10 \%$ or less: $0,20-40 \%: 1,40-50 \%: 2,60-80 \%$ or more: 3\}, $O_{E}=\{$ Long term side effects: 0, Severe Short term side effects: 1, Moderate Side effects: 2, Ignorable effects: 3 \}. Therefore, the set $O$ has 256 outcomes in total. Table 5 partly shows the outcome table with corresponding utilities. Utility considered here is a relative representation of preferences over a set of outcomes. It is essentially subjective and personal. However, we assume the patient gives the utility by a multiple regression equation according to his/her intuition. The utility formula that has been used in this paper is: $((T * 64+S * 16+$ $(E+4) * 4+C+1)$, where $T, S, E, C$ represent treatment efficiency, 5-year survival rate, side effects and cost or expense of treatment respectively. All variables take values from 0 to 3 in an order of betterment. We obtained the utility values by iterating the variables from the lowest utility to the highest utility incrementing one variable at a time. According to the formula of utility generation, outcome $o_{1}$ equals 17 . From the belief structure, we can now approximate the probabilities in three different attitudes of a decision-maker: namely Equative, Pessimistic and Optimistic and proceed to apply PT for overall value of each alternative. The mentioned attitudes are not the only attitudes that can be expressed by NY-DDM framework; many other attitudes can be expressed by changing the parameters of OWA operator.

Table 5. Outcome Table with Utility

\begin{tabular}{|c|c|c|}
\hline $\begin{array}{c}\text { Outcome } \\
\text { Number }\end{array}$ & Description & $\begin{array}{c}\text { Utility Value } \\
\left(T^{*} 64+S^{* 16+}\right. \\
(E+4) * 4+C+1)\end{array}$ \\
\hline$o_{1}$ & $\begin{array}{c}\text { Very Expensive, No } \\
\text { recovery, } \begin{array}{c}\text { So\% or less, Long term } \\
\text { Side Effects }\end{array}\end{array}$ & 17 \\
\hline$o_{2}$ & $\begin{array}{c}\text { Very Expensive, No recovery, } \\
10 \% \text { or less, Severe Short term } \\
\text { effects }\end{array}$ & 21 \\
\hline$o_{255}$ & $\begin{array}{c}\text { Inexpensive, Fast recovery, } 60- \\
80 \% \text { or more, Moderate Effects }\end{array}$ & 268 \\
\hline$o_{256}$ & $\begin{array}{c}\text { Inexpensive, Fast recovery, 60- } \\
80 \% \text { or more, Ignorable Effects }\end{array}$ & 272 \\
\hline
\end{tabular}

In case of PT application, it requires us to set a reference point (the point or value in the outcome list for which a decisionmaker possesses a neutral feeling). For this specific problem, we have taken the median value of all outcomes as a reference point assuming that ordinary patients choose it as a reference to judge if the result is a success or failure. The next important part is to apply value function and weighting function to acquire and analyze decisions in different attitudes. The value function $v(x)$ uses $\alpha$, explaining risk attitude and $\lambda$, called the loss aversion coefficient. It is widely known in different literature that $\alpha$ to be less than 1 whereas $\lambda>1$ resembles loss aversion [5]. In our previous experiment [29], we have used 48 combinations of $(\lambda, \alpha, \gamma)$ in evaluating the overall values of the alternatives to find decisions that closely represent a decision-maker's attitude towards risk. The co-efficient values that we have used to generate the 48 combinations of $(\lambda, \alpha, \gamma)$ are $\lambda=2.17,2.25,3.06,4.80 ; \alpha=0.10,0.32,0.52,0.88$ and $\gamma=0.25,0.50$, and 0.75 . Using these 48 combinations, we generated the overall value of each alternative by multiplied sum of the values obtained from Eq. (7) and Eq. (8). In [30], we explained that the combination $\lambda=4.80, \alpha=0.10, \gamma=0.50$ can acquire more feasible decisions along with a close representation to each attitude of a decision-maker in DM problems of health domain. Putting it differently, these parameters have been tuned so that the results would reflect the decision-maker's risk attitude which we believe as common risk attitude in our society.

In this paper, we have used $\lambda=4.80, \alpha=0.10, \gamma=0.50$ as coefficient values. As we mentioned before, when $\lambda$ (lossaversion coefficient) is greater than one, individuals are more sensitive to losses than gains. If $\alpha<1$, the value function exhibits risk aversion over gains and risk seeking over losses and when $\gamma<1$, low probabilities are overestimated and high probabilities are underestimated. Therefore, $\lambda=4.80$ indicates much sensitivity to even slight loss of health than gains and the coefficient $\alpha=0.10$ implies that a patient is very much riskaverse whenever gain is achieved. Using these values, we obtained the overall values of all alternatives. As for example, for case 1 , we obtained the combined $b b a$ value shown in Table 2. Among the overall values of 21 alternatives for the above combination, 'No cancer treatment' alternative has got the highest value in equative attitude and therefore it has been chosen as the decision of Case 1 .

\section{RESULT AND ANALYSIS}

The decisions in three different decision attitudes for ten different bbas (Table 3) have been derived by NY-DDM and the results along with the corresponding overall values are shown in Table 6 .

The decisions of Table 6 reveal the fact that actual humans with characteristics of usual risk- seeking and risk-averse might take different decisions depending on the attitudes about uncertainty which cannot be represented by normative decision models. In brief, actual humans might make different decisions due to combined effects of attitudes to risk and ignorance as well as the weighting function of probabilities. The result shows that in Case 1 where the combined $b b a$ emphasizes the no cancer stage, both equative and optimistic decision-maker chooses 'no cancer' treatment with (overall value of 0.4361 and 0.6670 respectively) whereas a pessimist selects surgery, level 1 (overall value: 0.1952). In case 2, equative, pessimistic and optimistic decision-maker selects chemotherapy: L1 (overall value 0.5019), clinical trial: L1 (overall value 0.4168 ) and radiation therapy: L4 (overall value 0.5805) respectively. From all of the decisions, it is understandable that a pessimistic decision-maker has a mindset that the worst is going to happen whereas an optimistic decision-maker has a completely opposite outlook of achieving the best outcome. An equative attitude lies almost in the middle of these two extremes. A close look at the overall values also support this fact because overall value of the chosen alternative of equative attitude in every case is 
higher than that of pessimistic attitude but lower than that of an optimist.

Table 6. Patient's Decision Regarding Treatment in Various Attitudes

\begin{tabular}{|c|c|c|c|}
\hline & Equative & Pessimistic & Optimistic \\
\hline \multirow[t]{2}{*}{ Case 1} & $\begin{array}{l}\text { No cancer } \\
\text { treatment }\end{array}$ & Surgery:L1 & $\begin{array}{ll}\text { No } & \text { cancer } \\
\text { treatment } & \end{array}$ \\
\hline & 0.4361 & 0.1952 & 0.6670 \\
\hline \multirow[t]{2}{*}{ Case 2} & $\begin{array}{l}\text { Chemotherapy: } \\
\text { L1 }\end{array}$ & Clinical Trial:L1 & $\begin{array}{l}\text { Radiation } \\
\text { Therapy:L4 }\end{array}$ \\
\hline & 0.5019 & 0.4168 & 0.5805 \\
\hline \multirow[t]{2}{*}{ Case 3} & $\begin{array}{l}\text { Chemotherapy: } \\
\text { L1 }\end{array}$ & Clinical Trial:L1 & $\begin{array}{l}\text { Radiation } \\
\text { Therapy: L4 }\end{array}$ \\
\hline & 0.4368 & 0.3847 & 0.4767 \\
\hline \multirow[t]{2}{*}{ Case 4} & $\begin{array}{l}\text { Targeted } \\
\text { Therapies:L2 }\end{array}$ & Surgery:L2 & $\begin{array}{l}\text { Chemotherapy: } \\
\text { L3 }\end{array}$ \\
\hline & 0.5159 & 0.4210 & 0.5934 \\
\hline \multirow[t]{2}{*}{ Case 5} & $\begin{array}{l}\text { Radiation } \\
\text { Therapy:L3 }\end{array}$ & Chemotherapy:L2 & Clinical Trial:L4 \\
\hline & 0.3679 & 0.1786 & 0.5049 \\
\hline \multirow[t]{2}{*}{ Case 6} & $\begin{array}{l}\text { Radiation } \\
\text { Therapy:L2 }\end{array}$ & $\begin{array}{l}\text { Targeted } \\
\text { Therapies:L3 }\end{array}$ & Surgery:L3 \\
\hline & 0.5699 & 0.3374 & 0.6335 \\
\hline \multirow[t]{2}{*}{ Case 7} & $\begin{array}{l}\text { Radiation } \\
\text { Therapy:L3 }\end{array}$ & $\begin{array}{l}\text { Targeted } \\
\text { Therapies:L3 }\end{array}$ & Surgery:L4 \\
\hline & 0.5247 & 0.3630 & 0.5997 \\
\hline \multirow[t]{2}{*}{ Case 8} & $\begin{array}{l}\text { Chemotherapy: } \\
\text { L2 }\end{array}$ & Clinical Trials:L2 & $\begin{array}{l}\text { Targeted } \\
\text { Therapies:L1 }\end{array}$ \\
\hline & 0.4381 & 0.3773 & 0.4742 \\
\hline \multirow[t]{2}{*}{ Case 9} & $\begin{array}{l}\text { Targeted } \\
\text { Therapies:L1 }\end{array}$ & Surgery:L1 & Chemotherapy:L2 \\
\hline & 0.5068 & 0.4154 & 0.5735 \\
\hline \multirow[t]{2}{*}{$\begin{array}{l}\text { Case } \\
10\end{array}$} & $\begin{array}{l}\text { Targeted } \\
\text { Therapies:L4 }\end{array}$ & Surgery:L4 & $\begin{array}{l}\text { Radiation } \\
\text { Therapy:L1 }\end{array}$ \\
\hline & 0.4707 & 0.3925 & 0.5285 \\
\hline
\end{tabular}

It is to be noted that we are considering a DM framework which falls under the category of descriptive decision-making theory. Therefore, we cannot comment that one decision is superior or inferior to another or we cannot obtain an optimum solution which is the trait of normative decisionmaking. Similarly, in NY-DDM, it is also not possible to declare any one solution of a problem to be the best since decisions vary depending on the attitudes of a decision-maker which is the basic tenet of a descriptive decision-making.

\section{CONCLUSION}

This paper develops a descriptive decision-making model that incorporates Dempster-Shafer Theory and Prospect Theory and illustrates its application in decision-making regarding lung cancer treatments. We have defined the lung cancer treatment decision-making problem as an EDMP where the uncertainty is defined by basic belief assignments of DST. In our study, we have also stressed the importance of multiple information sources in lung cancer staging similar to the reallife lung cancer diagnosis trajectory because proper treatment of lung cancer is highly dependent on appropriate staging. Basic belief assignments regarding the current stage of lung cancer obtained from each source are then combined by an evidence combination rule proposed by the authors in a previous research article. The proposed rule of evidence combination is based on weighted average where the weights are designated by incorporating reliability of the sources i.e. medical examinations of three different categories. The proposed combination rule has been proved to be an improvement of Murphy's combination in [12]. Upon receiving the combined bbas, the problem has been transformed into one under risk by probability approximation and PT is applied to the transformed DM problems. Apart from the three different attitudes mentioned in this paper, numerous human attitudes are possible to explain by changing the parameters of OWA operator.

The results presented in the preceding section reveal the fact that uncertainty creates diverse impact on people's decisions. Therefore, the selection of treatment by the patients of varying attitudes was also different based on their outlook toward uncertainty. We strongly believe that the proposed DM algorithm can be used to implement decision support systems for patients and their caregivers. This kind of patient centric decision support systems can be very effective at improving health care processes in acquiring knowledge to facilitate making informed decisions. It is possible to couple the patient-based decision support system with high-quality decision counseling so that patients may be allowed to weigh the benefits and limitations among the appropriate alternatives.

\section{REFERENCES}

[1] Simon, H.A., 1955, A behavioral model of rational choice, Quarterly J. of Economics, 99-118.

[2] Hanssen, S.O., 1994, Decision Theory-A Brief Introduction, Royal Institute of Technology, Stockholm, 6-15.

[3] Allais, M., 1979. The so-called Allais paradox and rational decisions under uncertainty, in Expected Utility Hypotheses and the Allais Paradox, eds. M. Allais and O. Hagen (Reidel, Dordrecht), 437-681.

[4] Ellsberg, D., 1961. Risk, ambiguity and the Savage axioms, Quarterly J. of Economics 75, 643-669.

[5] Kahneman, D. and Tversky, A., 1979 Prospect Theory: An analysis of decision under risk, Econometrica, Vol. 47(2), 263-292.

[6] Nusrat, E. and Yamada, K., 2013. A descriptive decision-making model under uncertainty: combination of Dempster-Shafer Theory and prospect theory, Int. J. Uncertainty, Fuzziness and Knowledge-based Systems, Vol. 21 (1), 79-102.

[7] Chilton, F. and Collett, R.A., 2008. Treatment choices, preferences and decision-making by patients with rheumatoid arthritis, Musculoskeletal Care, Vol. 6(1), 114.

[8] Wagner, E.H. et. al., 1995. The effect of a shared decision making program on rates of surgery for benign prostatic hyperplasia, Med. Care, Vol. 33, 765-770.

[9] Davidson, B.J. and Goldberg, S.L., 2003. Decisional regret and quality of life after participating in medical decision-making for early-stage prostate cancer, $B J U$ Intl. 91,14-17.

[10] Hellenthal, N. and Ellison, L., 2008. How patients make treatment choices, Nature Clinical Practice Urology, Vol. 5, No. 8.

[11] Shafer, G., 1976, A Mathematical Theory of Evidence, Princeton University Press, Princeton, NJ.

[12] Nusrat, E. and Yamada, K., 2012. An Approach of Lung Cancer Staging by Weighted Average and Reliability based Rule of Evidence Combination, J. of Advanced Computational Intelligence and Intelligent Informatics (submitted). 
[13] Knight, F. H., 1921, Risk, Uncertainty, and Profit. Houghton Mifflin, New York.

[14] Wakker, P., 2010, Prospect Theory for Risk and Ambiguity, Cambridge university press, New York.

[15] Schmeidler, D. 1989. Subjective probability and expected utility without additivity, Econometrica, Vol. 57, No. 3, 571-587,

[16] Quiggin, J., 1982. A theory of anticipated utility, J.Economic Behavior and Organization, Vol. 3, 323-343.

[17] Yager, R. R., 2004. Uncertainty modeling and decision support, Reliability Engineering and System Safety, Vol. 85, 341-354.

[18] Yager, R. R., 1992. Decision making under DempsterShafer uncertainties, Int. J. of General Systems, Vol. 20, 233-245.

[19] Yager, R. R., 1988. On ordered weighted averaging aggregation operators in multi-criteria decision making, IEEE Trans. on Systems, Man and Cybernetics, Vol.18, 183-190.

[20] Tacnet, J.M. and Dezert, J., 2011. Cautious OWA and evidential reasoning for decision making under uncertainty, in Proc. $14^{\text {th }}$ Int. Conf. on Information Fusion, Chicago, USA.

[21] Tversky, A. and Kahneman, D., 1992. Advances in Prospect Theory: Cumulative Representation of Uncertainty, J. of Risk and Uncertainty Vol. 5, 297-323.

[22] Tamura, H., 2005. Behavioral models for complex decision analysis, European J. of Operational Research, Vol.166, 655-665.
[23] Tamura, H. and Miura, Y., 2006. Value judgment of the sense of security for nursing care robots based on the prospect theory under uncertainty, Int. J. of Knowledge and System Sciences, Vol. 3, 28-33.

[24] Dubois, D. and Prade, H., 1982. On several representations of uncertain body of evidence, in Fuzzy Information and Decision Process, M.M. Gupta and E. Sanchez, Eds., North Holland publication, Amsterdam, 167-181.

[25] Neilson, W. and Stowe, J., 2002. A further examination of cumulative prospect theory parameterizations, The $J$. of Risk and Uncertainty, Vol.24 (1), 31-46.

[26] Nusrat, E. and Yamada, K., 2011. Different decision attitudes in decision-making under uncertainty, Congress of The Shin-Etsu Chapter of IEEE, The IEEE Shin-etsu Session, p.186, Niigata, Japan.

[27] Murphy, C.K., 2000, Combining belief functions when evidence conflicts, Decision Support Systems 29, 1-9.

[28] National Cancer Institute, National Institutes of Health, USA.

[29] Dempster, A.P., 1967, "Upper and lower probabilities induced by a multivalued mapping," Ann. of Math. Statist. 38, 325-339.

[30] Nusrat, E., Yamada, K. and Das, S, 2012. A Descriptive Decision-making Model of Patients' Treatment Decision using Dempster-Shafer Theory and Prospect Theory, Western Decision Sciences Institute 41st Annual Meeting, 302-307,Hawaii. 